\title{
"Dynamic links between ICT, transport energy, environmental degradation and growth: empirical evidence from Tunisia"
}

\begin{tabular}{ll} 
AUTHORS & $\begin{array}{l}\text { Mounir Ben Mbarek } \\
\text { Nahed Zghidi }\end{array}$ \\
\hline ARTICLE INFO & $\begin{array}{l}\text { Mounir Ben Mbarek and Nahed Zghidi (2017). Dynamic links between ICT, } \\
\text { transport energy, environmental degradation and growth: empirical evidence from } \\
\text { Tunisia. Environmental Economics, 8(3), 76-83. doi:10.21511/ee.08(3).2017.08 }\end{array}$ \\
\hline DOI & http://dx.doi.org/10.21511/ee.08(3).2017.08 \\
\hline RELEASED ON & Tuesday, 26 September 2017 \\
\hline RECEIVED ON & Thursday, 17 August 2017 \\
\hline ACCEPTED ON & Monday, 18 September 2017 \\
\hline LICENSE & $\begin{array}{l}\text { (co) EY-No } \\
\text { Inis work is licensed under a Creative Commons Attribution-NonCommercial } 4.0\end{array}$ \\
\hline JOURNAL & "Environmental Economics" \\
\hline ISSN PRINT & $1998-6041$ \\
\hline ISSN ONLINE & $1998-605 X$ \\
\hline PUBLISHER & LLC “Consulting Publishing Company “Business Perspectives" \\
\hline FOUNDER & LLC “Consulting Publishing Company “Business Perspectives"
\end{tabular}

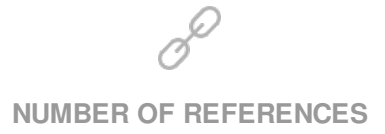

17
NUMBER OF FIGURES

0
NUMBER OF TABLES

5

C The author(s) 2022. This publication is an open access article. 


\title{
Dynamic links between ICT, transport energy, environmental degradation and growth: empirical evidence from Tunisia
}

\begin{abstract}
The transport sector, particularly road transport, is a major factor in the overall emissions balance of the substances involved in air pollution for the majority of developing countries. This paper investigates the dynamic links between information and communication technology (ICT), transport energy, environmental degradation and growth for Tunisia. The authors used a Johansen co-integration analysis to determine this econometric relationship using data during 1990-2015. In order to test the Granger causality links in the short and long run, a panel Vector Error Correction Model is used. The variance decomposition is used to confirm the existing links between the different variables. Different results are found. These findings show the existence of bidirectional in short- and long-run causality between transport energy and $\mathrm{CO} 2$ emissions. By cons, ICT does not minimize significantly pollution in Tunisia. These findings are very important for the transport sector and in terms of the choice of government policy decisions in order to minimize the pollution.
\end{abstract}

Keywords: transport energy, environmental degradation, air pollution, environmental degradation and growth.

JEL Classification: O13, Q53.

Received on: $17^{\text {th }}$ of August July, 2017.

Accepted on: $18^{\text {th }}$ of September, 2017.

\section{Introduction}

Information and communication technologies (ICTs) have long been perceived primarily in terms of their undoubted contribution to the productivity of the economy and the well-being of the population.

According to the European Commission, ICT contributes $2 \%$ to global emissions of greenhouse gases. This figure could, however, increase due to the very strong growth of the market and despite technological developments which would make it possible to reduce, in particular, the levels of electricity consumption. Notwithstanding this remark, the first challenge is to allow, through technological innovation, to reduce the remaining $98 \%$ of emissions. In fact, ICTs can promote the adoption of more environmentally friendly behavior throughout the economy. They are already playing a decisive role in the systems development to support environmental decision-making and in the possibility that they offer different actors to modulate their behavior according to management and the sustainable use of natural resources. In particular, satellite remote sensing makes it possible to analyze by satellite the evolution of certain phenomena (drought, desertification, pollution of land, air and water, urbanization ...) and to

\footnotetext{
(c) Mounir Ben Mbarek, Nahed Zghidi, 2017.

Mounir Ben Mbarek, Ph.D., Lecturer, Higher Institute of Management of Gabes, Unversity of Gabes, Gabes, Tunisia.

Nahed Zghidi, Ph.D., Commercial High School of Sfax, University of Sfax, Tunisia.

This is an Open Access article, distributed under the terms of the Creative Commons Attribution-NonCommercial 4.0 International license, which permits re-use, distribution, and reproduction, provided the materials aren't used for commercial purposes and the original work is properly cited.
}

anticipate the consequences for their limiting or neutralization.

Transport considered among the most sector which has the fastest growing energy consumption and consequently carbon dioxide emissions worldwide. In fact, transport sector consumes about $20 \%$ of global energy use and it is responsible for nearly one quarter of global energy related greenhouses emissions "carbon dioxide" with $75 \%$ of these emissions are due to road transport energy use. These trends and figures are the results and consequences of increasing population and economic development at the cost of the pollutions and environmental degradation.

Due to the development of ICT, we have been able to reduce the ecological footprint of transport and to develop public transport modes (new trams, GPS equipment to optimize journeys, urban bicycle ...). The automotive of 2020, condensed from ICT, will have the means to define and realize the journeys, by communication with the infrastructures, for optimal security and still reduced energy consumption.

It is worth noting that there has not been a study touched the role of ICT development in transport energy use, $\mathrm{CO} 2$ emissions and economic growth in the developing economies like Tunisia. In addition, as far as we know, doesn't any of empirical studies that focused on investigating the causal links among ICT, environment-transport-energy and growth via the cointegration and VECM model.

The dynamic links between transport energy use and environmental degradation measured by greenhouse gases (GHG) has long been a subject of constant concern and research. In fact, the transport energy consumption and the $\mathrm{CO} 2$ emissions are continuously 
increasing in different countries, whether for developed or developing economies, whose developed economy, trade opening and GDP growth can cause the development of transport sector and therefore the carbon emissions. Whether economic development creates problems for environmental protection or improves environmental degradation may be studied through the use of econometric and statistic methods. In fact, in the field of environmental economics, the literature on transport energy and greenhouse gases (GHG) has attempted to address several and major questions in different lines of research.

Today and despite the benefits that can be associated with public transport, the automobile remains the preferred means of urban.

Le Breton (2001) found that the difficulties facing the public transport from the 60s are behind five leading causes namely, the priority given to land at the expense of a more focused development of cities, preference enhanced by individual modes of housing and transport, the implementation of an urban development model which leads to a dissociation of activities by specific areas favorable to the automobile, lack of foresight among users of the transport networks and the lack of coordination between the local authority and the operators.

In this respect, improving the overall efficiency of public transport networks was a major challenge. The development of infrastructure that meets mobility needs appears to be necessary to make the public transport sector more efficient. It may also be appropriate to use the most advanced techniques as they are developed in so-called intelligent transport systems.

The use of the intelligent transportation system is a major challenge. It brings a technological benefit to the power of computers and electronics, and a social benefit since public transport by becoming more accessible. Bruglieri et al. (2015) have shown that a real-time transport planning system improves the functioning of the public transport system; it becomes very useful for public transport users. Intelligent transport systems make it possible to boost public transport insofar as they make it possible to improve the conditions of transport use (Stelzer et al., 2016).

Public transport is seen as an attractive alternative to cars. Rising environmental concerns and measures limiting excessive use of automobiles have strengthened the attractiveness of public transport (Boyle, 1990).

Cars are often less efficient than public transport, given their economic, social and environmental costs. The advantage of public transport in relation to cars is indisputable in terms of air pollution and the rational use of energy. Public transport is therefore at the heart of environmental and social issues. It plays an important role in protecting air quality. Air pollution caused by transport causes health problems. Many studies have shown that the use of public transport to the detriment of the automobile can lead to major improvements in health problems (Rojas-Rueda et al., 2013; Wang, 2016).

Beyond the benefits of public transport, several facets of the technology used reinforce its positive impact on the environment. In addition to electrically powered vehicles, there has been no question of making buses less polluting. Nearly $60 \%$ of Swedish buses use renewable energies in 2014 compared to $8 \%$ in 2007 (Xylia \& Silveira, 2017). The emission of CO2 takes an important place since it contributes strongly to the greenhouse effect. Moving to a carbon-free world today is imperative. Public transport is a major player in the fight against climate change, participating in global efforts to save energy resources. The electric bus reduces the use of petroleum by 85 to $87 \%$ compared to a diesel bus and leads to a reduction of 32 to $46 \%$ in fossil fuel use and 19 to $35 \%$ in $\mathrm{CO} 2$ emissions (Zhou et al., 2016).

The investigations related to the relationship between growth and transport activity become a very critical topic (Saidi \& Hammami, 2017), at both national and international level. In addition, several research studies argue the positive effects of the phenomenon and indicate that the economic development is the mainstay of any country's economic development (Kim, 2002; Fedderke et al., 2006; Pradhan \& Bagchi, 2013; Saidi \& Hammami, 2017).

Recently, Alshehry and Belloumi (2017) studied the relationship between transport carbon dioxide emissions, energy consumption related to road transport and economic activity for Saudi Arabia. They attempted to check for the environmental Kuznets curve (EKC) hypothesis over the period 1971-2011 for Saudi Arabia by using the autoregressive distributed lag (ARDL), co-integration procedure and Granger causality tests. Their findings confirm the inexist of inverse $\mathrm{U}$ relationship between transport $\mathrm{CO} 2$ emissions and economic growth in this country. They found also a bidirectional link between transport $\mathrm{CO} 2$ emissions and road transport energy use in the short and long run.

\section{Overview on ICT and transport energy sector in Tunisia}

The Tunisian economy, among the most competitive economies on the African and Arab scale, offers businesses an adequate environment for the development of their value-added activities. These factors ensure social inclusion and reduce the digital divide through better access to information and knowledge, supporting the creation of added value, guaranteeing the sustainability of organizations and 
jobs, by supporting entrepreneurship and stimulating innovation, improving the competitiveness of the company, across all sectors, by investing in ICT and positioning in the digital economy, ensuring Tunisia's transition to the digital world through the creation of a suitable regulatory framework, governance and security environment.

According to the annual report of the International Telecommunication Union (ITU) published on Tuesday 22 November 2016, Tunisia ranks 95th out of a total of 175 countries analyzed in the ICT development index. Tunisia, which occupies the same ranking as the year 2015, comes just ahead of its neighbors, Morocco (96th), Egypt (100th) and Algeria (103rd), but lags far behind other Arab countries such as Bahrain (29th), United Arab Emirates (38th), Saudi Arabia (45th), Qatar (46th), Kuwait (53rd), Sultanate of Oman (59th) and Lebanon (66th). At the top of the table are South Korea (1st), Iceland (2nd), Denmark (3rd), Switzerland (4th). The IDI index takes into account more than ten indicators, particularly access to and use of technologies and skills in this area.

According to the national agency for energy conservation, transport sector takes the second place in Tunisia, in terms of energy consumption; about $34 \%$ in 2010 after industrial sector with $35 \%$ of total energy consumption. Transport energy has been increased from $827 \mathrm{~kg}$ tone oil equivalent (ktoe) in 1980 to 1821 ktoe in 2010. In fact, several factors can explain these data: first, pricing and taxation of fuel used by road transport vehicles, second, the vehicle's park structure and important road infrastructure investments. The transport sector in Tunisia is considered as the most important consumption of energy from fossil combustibles with $99.5 \%$ of petroleum products in 2010. This increased consumption is explained by the importance of road transport activity that is closely linked to combustible fossils use, especially diesel (60.6\%) and gasoline (25\%) in 2010.

Undoubtedly, the rational use of energy constitutes a vector of energy efficiency that plays an important role in the economic and social development of the country. In this regard, Tunisia became aware of the importance of energy control in all sectors at an early stage, by enacting the appropriate legislative texts and creating mechanisms and structures to encourage all parties to renewable energy use, and it was imperative to take the necessary steps to reduce this energy bill and reduce greenhouse gas emissions.

According to the national agency for energy conservation, the transport sector will be the first energy consumer with more than $30 \%$ of the final energy balance in 2030. Structural changes and technological improvements are likely to reduce this consumption considerably. This sector is very promising in energy saving. However, in the short term, transport contributes relatively little to cumulative savings.

\section{Methodology}

The empirical study presented in this article is carried out using the co-integration analyses and Granger causality test. In fact, Granger causality test fits a standard vector autoregressive (VAR) model and vector error correction model (VECM) (Ben Mbarek et al., 2017). The VAR model, which was proposed by Christopher Sims in 1980, is widely used as an econometric tool to detect in a comprehensive and dynamic way several interdependent economic variables in stationary and non-stationary time series (see, for example, Dees et al., 2007 and Gao, 2009, among others). The popularity of autoregressive vector model (VAR) is related to their flexibility of use and their ability to test economic assumptions.

According to the seminal work introduced by Sims (1980), the VAR model was applied to a vast range of empirical topics and especially energy, environmental and economic variables. It is an approach that can be used to achieve comprehensive dynamic links between multiple variables and has the capacity to obtain predictions of relative time series (see Gao et al., 2009). The dynamic causality can be estimated and presented by the regression of lagged terms (AIC and Schwartz are measures of the quality of a proposed statistical model) from each endogenous variable to all studied variables of the model in the short and long term, by which we can detect the impact from itself and the others. The basic expression is as follows:

$y_{t}=A_{1} y_{t-1}+\ldots+A_{p} y_{t-p}+B X_{t}+U_{t}, t=(1,2, \ldots, T)$,

where $y_{t}$ is the endogenous variable vector and $X_{t}$ is the exogenous variable vector; $p$ is the lagged intervals for endogenous variables; $T$ indicates the number of samples; $U_{t}$ measures the white noise of the time series of vectors.

Following this procedure, we use the Granger causality test (Granger, 1988) based on the vector error correction model (VECM) in order to detect the nexus between ICT, transport energy, environmental degradation and growth. However, this test is conditional on the stationarity of the involved time series variables. In fact, if the subjacent time series are non-stationary, the test statistics of Granger causality (Sims, 1980) based on the vector autoregressive model is invalid. Therefore, we test the order of integration for all variables in the first step. If the variables are stationary at the same difference, the co-integration and VECM is recommended to investigate the dynamic relationship (short- and long-run) between the used variables. Thereafter and in the next step, we employ Johansen co- 
integration tests in order to examine the long-term links between the studied variables.

We use the Choleski decomposition variance (VDC) to provide an indication of the importance of the causal impact of one selected variable on another variable. A choleski decomposition analysis is used in a VECM, according to Ghali and El-Sakka (2004).

\section{Empirical findings}

3.1. Data and descriptive statistic. Table 1 summarizes the description associated with the four used variables. The empirical study is based on 26 annual observations. As a summary, the Mean of FFEC is highest and that of LICT is the lowest. It is evident from this table also that standard deviation (Std. Dev.) of CO2 is highest and that of GDP is the lowest. All variables have negative value of skewness by except the GDP indicating that the distribution is skewed to the left, with more observations on the right. All variables have low values of Skewness. The statistic of Jarque-Bera shows that all variables used in the analysis have a normal distribution. Finally, all variables are downloaded from the World Bank's Development Indicators.

Table 1. Data and descriptive statistic of variables

\begin{tabular}{|l|c|c|c|c|}
\hline & LICT & LGDP & CO2 & FFEC \\
\hline Mean & 19.32843 & 24.16698 & 23.55844 & 87.17610 \\
\hline Median & 19.18300 & 24.16883 & 22.83352 & 87.03364 \\
\hline Maximum & 20.14039 & 24.59614 & 29.45470 & 88.43208 \\
\hline Minimum & 18.67603 & 23.63226 & 19.87952 & 85.96209 \\
\hline Std. Dev. & 0.472073 & 0.312659 & 2.402970 & 0.666859 \\
\hline Skewness & 0.518245 & -0.187791 & 0.932855 & 0.516630 \\
\hline Kurtosis & 1.853965 & 1.698526 & 3.342359 & 2.424444 \\
\hline Jarque-Bera & 2.586682 & 1.987803 & 3.897920 & 1.515465 \\
\hline Probability & 0.274353 & 0.370130 & 0.142422 & 0.468728 \\
\hline Sum & 502.5391 & 628.3414 & 612.5195 & 2266.579 \\
\hline Sum Sq. Dev. & 5.571329 & 2.443891 & 144.3566 & 11.11752 \\
\hline Observations & 26 & 26 & 26 & 26 \\
\hline
\end{tabular}

3.2. Unit root tests. In the early 1980s, many studies revealed that most macroeconomic series are non-stationary. In fact, the results of econometric regressions may be misleading if preliminary statistical tests are not performed on the time series used. To this end, the unit root tests of Augmented Dickey-Fuller (ADF) and Phillips-Perron (PP) are performed. Therefore, to check the stationarity of all variables, we test the existence of the "unit root" in the complete sample, through two tests that are used: ADF and $\mathrm{PP}$, the results are presented in Table 2, which shows the values of the Student statistic $(t)$ for the variables at level and at first difference. Thus, the unit root test indicates that all series are integrated of order one (I (1)) and therefore stationary in first difference. Table 3 below also shows the results of the unit root tests.

Table 2. Unit root test (Augmented Dickey-Fuller (ADF) and Phillips-Perron (PP))

\begin{tabular}{|c|c|c|c|c|c|c|}
\hline \multirow[t]{2}{*}{ Variables } & \multicolumn{3}{|c|}{ Level } & \multicolumn{3}{|c|}{ 1st difference } \\
\hline & (i) & (ii) & (iii) & (i) & (ii) & (iii) \\
\hline \multicolumn{7}{|c|}{ ADF test } \\
\hline LGDP & 5.286767 & -1.996159 & -0.387882 & $-3.825507^{\star *}$ & $-4.085698^{\star}$ & $-4.750207^{\star}$ \\
\hline FFEC & 0.491874 & -1.785280 & -2.367795 & $-7.596853^{\star}$ & $-7.665037^{\star}$ & $-7.605455^{*}$ \\
\hline LICT & 1.114645 & -0.623396 & -2.254948 & $-5.291907^{\star}$ & $-5.560317^{\star}$ & $-5.493509^{\star}$ \\
\hline $\mathrm{CO} 2$ & 0.517082 & -1.660872 & $-3.268570^{\star \star *}$ & -3.878107 & $-3.854931^{*}$ & $-3.804509^{*}$ \\
\hline \multicolumn{7}{|c|}{ Phillips-Perron test } \\
\hline LGDP & 8.858244 & -1.996159 & -0.387882 & $-3.420561^{* *}$ & $-4.083515^{*}$ & $-4.754470^{*}$ \\
\hline FFEC & 0.718547 & -1.650565 & -2.229908 & $-7.596853^{\star}$ & $-7.563362^{*}$ & $-7.703566^{\star}$ \\
\hline LICT & 1.717696 & -0.269405 & -2.258951 & $-5.318338^{*}$ & $-5.894190^{*}$ & $-6.415034^{*}$ \\
\hline $\mathrm{CO} 2$ & 0.517082 & -1.660872 & -2.183726 & $-3.894111^{*}$ & $-3.870713^{\star *}$ & $-3.817689^{* \star}$ \\
\hline
\end{tabular}

Note: (i): without intercept, (ii): with an intercept, and (iii): with an intercept and trend. $* * *, * *$ and $*$ : asterisks mean a p-value less than $1 \%, 5 \%$ and $10 \%$. Critical levels in the model: (i) $-2.60(1 \%),-1.95(5 \%)$ and $-1.61(10 \%)$. Critical levels in: (ii) $-3.51,-2.89$ and -2.58 . Critical levels in: (iii) $-4.04,-3.40$ and -3.15 . 
3.3. Cointegration analysis. The study of cointegration makes it possible to test the existence of a stable long-term relationship between two nonstationary variables, including delays and exogenous variables. There are several tests of co-integration, the most general being that of Johansen. Since all the series are integrated of order one, the cointegration relationship between them are established by using Johansen co-integration test. Two series ( $\mathrm{x}$ and $\mathrm{y}$ ) are said to be co-integrated if the two following conditions are satisfied: they are affected by a stochastic trend of the same order of integration and a linear combination of these series makes it possible to reduce to a series of order of lower integration. We use the maximum likelihood estimation (MLE) method of Johansen and Juselius (1990). The Johansen's co-integration test is based on two different likelihood ratio statistics (LR): the trace statistic and the maximum eigenvalue statistics. The co-integration test implies the existence of causality links between the series, but it does not indicate the direction of causality. The results of co-integration tests reported in Table 3 indicate the existence of a long-run relationship between ICT, transport energy, environmental degradation and growth.

Both the maximum eigenvalue and the trace statistic reject the null hypothesis of no cointegration.
Table 3. Results of Johansen cointegration test

\begin{tabular}{|c|c|c|c|c|}
\hline \multicolumn{4}{|c|}{ Unrestricted cointegration rank test (Trace) } & \\
\hline Hypothesized & & Trace & 0.05 & \\
\hline No. of $\mathrm{CE}(\mathrm{s})$ & Eigenvalue & Statistic & Critical value & Prob.** \\
\hline None * & 0.781544 & 83.28428 & 54.07904 & 0.0000 \\
\hline At most 1 * & 0.708025 & 48.29736 & 35.19275 & 0.0012 \\
\hline At most 2 & 0.372729 & 19.98237 & 20.26184 & 0.0546 \\
\hline At most 3 * & 0.331302 & 9.255722 & 9.164546 & 0.0480 \\
\hline
\end{tabular}

Note: trace test indicates 2 cointegrating(s) at the 0.05 level * denotes rejection the hypothesis at the 0.05 level ** P-values of MacKinnon-Haug-Michelis (1999).

3.4. Granger causality tests. After examining the long run links between the variables and the existing of co-integration, a causality test is designed to detect the dynamic causal direction between the two time series. In fact, the approach of Granger (1968) for the formalization of the causality concept has certainly had big echoes among researchers in economics. The basis of Granger causality test is the dynamic relationship between the variables in the short- and long-run. According to Granger's theorem of representation, any co-integrated system implies the existence of an error correction mechanism that prevents the variables from deviating too much from their long-term equilibrium. To ascertain the direction of causality between the studied variables, we estimate the errorcorrection model (ECM). The vector errorcorrection model VECM with our variables can be written as follows:

$$
\begin{aligned}
& \Delta L G D P_{t}=\alpha_{1}+\sum_{i=1}^{k} \beta_{1 i} \Delta L G D P_{t-i}+\sum_{i=0}^{k} \delta_{1 i} \Delta L I C T_{t-i}+\sum_{i=0}^{k} \lambda_{1 i} \Delta C O 2_{t-i}+\sum_{i=1}^{k} \gamma_{1 i} \Delta F F E C_{t-i}+\psi_{1} \varepsilon_{T-1}+\xi_{1 t} \\
& \Delta L I C T_{t}=\alpha_{2}+\sum_{i=1}^{k} \beta_{2 i} \Delta L G D P_{t-i}+\sum_{i=0}^{k} \delta_{2 i} \Delta L I C T_{t-i}+\sum_{i=0}^{k} \lambda_{2 i} \Delta C O 2_{t-i}+\sum_{i=1}^{k} \gamma_{2 i} \Delta F F E C_{t-i}+\psi_{2} \varepsilon_{T-1}+\xi_{2 t} \\
& \Delta C O 2_{t}=\alpha_{3}+\sum_{i=1}^{k} \beta_{3 i} \Delta L G D P_{t-i}+\sum_{i=0}^{k} \delta_{3 i} \Delta L I C T_{t-i}+\sum_{i=0}^{k} \lambda_{3 i} \Delta C O 2_{t-i}+\sum_{i=1}^{k} \gamma_{3 i} \Delta F F E C_{t-i}+\psi_{3} \varepsilon_{T-1}+\xi_{3 t} \\
& \Delta F F E C_{t}=\alpha_{4}+\sum_{i=1}^{k} \beta_{4 i} \Delta L G D P_{t-i}+\sum_{i=0}^{k} \delta_{4 i} \Delta L I C T_{t-i}+\sum_{i=0}^{k} \lambda_{4 i} \Delta C O 2_{t-i}+\sum_{i=1}^{k} \gamma_{4 i} \Delta F F E C_{t-i}+\psi_{4} \varepsilon_{T-1}+\xi_{4 t}
\end{aligned}
$$

where $\Delta$ is the difference operator, $\alpha, \beta, \delta, \lambda, \gamma$ and $\psi$ are parameters for estimation, $t$ is the lag order, $\varepsilon_{t-p}$ is an error term. To test whether the Granger causality runs from LICT to GDP, the null $\left(H_{0}\right)$ hypothesis is: $H_{0}$ : $\delta_{1 i}=0, \mathrm{i}=1,2, \ldots \ldots \ldots p$; If $H_{0}$ is rejected, i.e., at least one of $\delta_{1 i}$ is not equal to zero, then it suggests that the past value of $L I C T$ has a significant linear predicative power on the current value of $G D P$. It normally denotes that $L I C T$ Granger causes $G D P$, and vice versa.
After validating the stationarity of the data, we can test a causal relationship between the time series. At this step of the study, we can empirically apply the Granger causality test to our variables and analyze the results. The test was performed on all the variables and intersections between the pairs of variables taken into account. Crossing couples which have not yielded significant results will not be discussed in this section. We perform a VECM model based on Granger causality test to identify the direction of causality (running from $\mathrm{x}$ to $\mathrm{y}$...) between ICT, transport energy, environmental 
degradation and growth measured by GDP. The long-run causality is captured by a significant t-test on a negative coefficient of the lagged errorcorrection term $E C M_{t-1}$.

Based on co-integration analysis, the VECM presented in equations (2), (3), (4) and (5) is employed to determine the direction of causality in the short and long run using Granger causality tests. These results are shown in Table 5. Results show that there is a unidirectional links running from transport energy consumption to economic growth measured by LGDP at $1 \%$ level of significance in the short and long run. Unidirectional relationship running from $\mathrm{CO} 2$ emissions to economic growth also is found at $1 \%$ level of significance in the short and long run. In fact, the Tunisian economy is based in the non-renewable energy use that considered as a principal factor of the greenhouse emissions. On the other hand, there is a big interdependence between $\mathrm{CO} 2$ emissions and transport energy consumption explained by the bi-directional relationship at the $5 \%$ level of significance in the short run.

Table 4. The VECM Granger causality analysis

\begin{tabular}{|c|c|c|c|c|c|}
\hline \multicolumn{5}{|c|}{ Short run } & Long run \\
\hline $\begin{array}{c}\text { Dependent } \\
\text { variables }\end{array}$ & $\mathrm{D}(\mathrm{LGDP})$ & $\mathrm{D}(\mathrm{FFEC})$ & $\mathrm{D}(\mathrm{LICT})$ & $\mathrm{D}(\mathrm{CO} 2)$ & $E C M_{t-1}$ \\
\hline $\mathrm{D}(\mathrm{LGDP})$ & & $\begin{array}{c}7.667876^{*} \\
(0.0056)\end{array}$ & $\begin{array}{c}0.000472 \\
(0.9827)\end{array}$ & $\begin{array}{c}19.61362^{*} \\
(0.0000)\end{array}$ & $\begin{array}{c}- \\
0.033396^{*} \\
{[-6.47515]}\end{array}$ \\
\hline $\mathrm{D}(\mathrm{FFEC})$ & $\begin{array}{c}0.511289 \\
(0.4746)\end{array}$ & & $\begin{array}{c}0.210911 \\
(0.6461)\end{array}$ & $\begin{array}{c}6.119163^{* *} \\
(0.0134)\end{array}$ & $\begin{array}{c}0.149319^{*} \\
{[-0.94429]}\end{array}$ \\
\hline $\mathrm{D}(\mathrm{LICT})$ & $\begin{array}{c}0.011497 \\
(0.9146)\end{array}$ & $\begin{array}{c}0.174408 \\
(0.6762)\end{array}$ & & $\begin{array}{c}0.023234 \\
(0.8788)\end{array}$ & $\begin{array}{c}-0.041334 \\
{[-0.46898]}\end{array}$ \\
\hline $\mathrm{D}(\mathrm{CO} 2)$ & $\begin{array}{c}1.639424 \\
(0.2004)\end{array}$ & $\begin{array}{c}4.660298^{* *} \\
(0.0309)\end{array}$ & $\begin{array}{c}0.045703 \\
(0.8307)\end{array}$ & & $\begin{array}{c}0.547165 \\
{[1.02228]}\end{array}$ \\
\hline
\end{tabular}

Notes: ECT represents the coefficient of the error correction term. $*, * *$ and $* * *$ significant at $1 \%, 5 \%$ and $10 \%$ level

3.5. Variance decomposition. The VAR models are often analyzed through their dynamics and this via the simulation of random shocks and the analysis of the decomposition of their variance. The variance decomposition (VD) indicates the proportion of the movements in the dependent variables which are due to their "own" impacts and against shocks to the other variables. In fact, after estimating these regressions, we can use the residuals to decompose the variance. This will allow us to determine the contribution of past values of each model variable to the variance prediction of one or other of the model variables in the future. This method does not allow assessing the percentage of the variance of the forecast error that explained by each variable in absolute terms, but only in relative terms. The VD measures the quantitative effect that the shocks have on the variables (see Enders, 2004). On the other hand, Diebold and Yilmaz (2009) introduce a volatility spillover (VS) measure based on forecast error variance decompositions (FEVD) from vector autoregressions (VAR (p)). Considering N stationary variables VAR (p),

$$
y_{i}=A \sum_{i=1}^{p} \Phi_{i} y_{t-1}+\varepsilon_{i},
$$

in which where $y_{i}$ is a $(4 \times 1)$ vector of jointly determined endogenous variables, $\varepsilon \rightarrow(0, \theta)$ is the vector of IID disturbances, $\phi_{1}$ through $\phi_{p}$ are (4 $\times 4$ ) coefficient matrices, $A$ is a vector of constants. In addition, Diebold and Yilmaz (2012) used the generalized VAR framework proposed by Pesaran and Shin (1998); they constructed a variance decomposition invariant to commanding. Let us denote the generalized forecast error variance decompositions by:

$$
\theta_{i j}^{g}(H)=\frac{\sigma_{i j}^{-1} \sum_{h=0}^{H-1}\left(e_{i}^{\prime} A_{h} \sum_{e_{j}}\right)^{2}}{\sum_{h=0}^{H-1}\left(e_{i}^{\prime} A_{h} \sum_{A_{h}}^{\prime} e_{i}\right)},
$$

where $\Sigma$ is the variance matrix for the error vector $\varepsilon$, $\sigma_{i j}$ is the standard deviation of the error term for the $j^{\text {th }}$ equation, and $e_{i}$ is the selection vector, with one as the $i^{\text {th }}$ element and zero otherwise.

Table 5 shows the results of the estimate forecast error of variance decomposition for each variable. The decomposition variance is taken temporally with respect to the source of disturbance. In fact, median forecast error of variance decompositions are computed to a horizon of two, four, six and eight years. The impact of FFEC on GDP is 24.29 percent by the first two years; this effect increases for the remaining periods and up to 83.55 in the eight periods. This result shows that the economic growth measured by GDP is more dependent by transport energy compared to the other variables. Our results show that the most of the variation in the forecast error for $\mathrm{CO} 2$ emissions comes from shocks to transport energy consumption which exceeds $29.18 \%$ after 8 periods. In fact, transport sector is responsible for more than a quarter of national emissions of greenhouse gases in Tunisia. The $\mathrm{CO} 2$ emissions are less explained by the ICT. Result shows that for a time horizon of 4 years, almost $2.01 \%$ of the variation $\mathrm{CO} 2$ is explained by the ICT. This variation decreases less than $2 \%$ at the 6 th period and up $1.81 \%$ in the $8^{\text {th }}$ period $(8$ years). The influence of the 
transport energy consumption on $\mathrm{CO} 2$ emissions is taken into account, while the direct effect of GDP on
ICT is almost stable during 8 years, $2.36 \%$ of the effects on GDP in 2 years, and this cross until $2.09 \%$ in 8 years.

Table 5. Variance decomposition: Cholesky ordering: LNGDP FFEC LNICT CO2

\begin{tabular}{|l|c|c|c|c|c|}
\hline Period & S.E. & LNGDP & FFEC & LNICT & CO2 \\
\hline \multicolumn{7}{|c|}{ Variance decomposition of LNGDP } \\
\hline 2 & 0.021636 & 63.29042 & 24.29938 & 2.904420 & 9.505782 \\
\hline 4 & 0.037580 & 29.75749 & 48.00625 & 6.798376 & 15.43789 \\
\hline 6 & 0.059070 & 13.71315 & 72.74176 & 6.851895 & 6.693188 \\
\hline 8 & 0.085552 & 6.993442 & 83.55777 & 6.200802 & 3.247984 \\
\hline \multicolumn{7}{|c|}{ Variance decomposition of FFEC } \\
\hline 2 & 0.517704 & 3.568371 & 67.34309 & 0.310023 & 28.77852 \\
\hline 4 & 0.704650 & 4.413621 & 44.51950 & 0.309342 & 50.75754 \\
\hline 6 & 0.819301 & 4.782577 & 37.90308 & 0.237382 & 57.07696 \\
\hline 8 & 0.920565 & 4.745090 & 32.76622 & 0.188516 & 62.30018 \\
\hline \multicolumn{7}{|c|}{ Variance decomposition of LNICT } \\
\hline 2 & 0.305377 & 2.364488 & 0.101633 & 97.19618 & 0.337698 \\
\hline 4 & 0.420565 & 2.341398 & 1.368388 & 95.08058 & 1.209636 \\
\hline 6 & 0.510216 & 2.242186 & 2.926046 & 93.22668 & 1.605088 \\
\hline 8 & 0.588169 & 2.093655 & 4.832679 & 91.05330 & 2.020371 \\
\hline \multicolumn{7}{|c|}{ Variance decomposition of CO2 } \\
\hline 2 & 2.267525 & 0.842878 & 22.41637 & 1.764821 & 74.97593 \\
\hline 4 & 3.198119 & 1.445495 & 25.58898 & 2.010333 & 70.95519 \\
\hline 8 & 3.855313 & 1.395904 & 27.61469 & 1.922053 & 69.06735 \\
\hline
\end{tabular}

\section{Conclusion and implications}

This study aims to investigate the dynamic relationship between transport energy consumption, economic growth, ICT's and carbon emissions in Tunisia during the period 1990-2015. The main results show that transport energy increases the $\mathrm{CO} 2$ emissions in Tunisia. Otherwise, there is not a significant effect of ICT in $\mathrm{CO} 2$ emissions. These results are confirmed by the Granger causality test and the variance decomposition.

Thus, such an in-depth knowledge of the transport sector will make it possible to evaluate the potential of rational energy use, reduction of pollution and greenhouse gas emissions and to establish programs of action for rational energy use in this sector. However, it should be noted that Tunisia's energy policy is focused on controlling energy demand, diversifying sources of technical production and supply, developing research in the energy sector, ensuring the existence transport infrastructure and energy storage adapted to consumer needs. It is within this framework that the National Agency for Energy Management, which promotes energy savings, particularly in the sectors of everyday use (housing, offices, shops, transport), where consumption is high, as well as the promotion of renewable energies. In the same context, these findings recommend, to encourage and support the creation of freight plants, in particular by setting up specific financing mechanisms. In addition, the strategy must include a real encouragement of rail for the transport of goods. In this context, the Tunisian National Railway Company will be able to promote this service technically and commercially.

\section{References}

1. Ajanovic, A., Dahl, C., \& Schipper, L. (2012). Modelling transport (energy) demand and policies - An introduction. Energy Policy, 41, 3-16.

2. Alshehry, A. S., \& Belloumi, M. (2017). Study of the environmental Kuznets curve for transport carbon dioxide emissions in Saudi Arabia. Renewable and Sustainable Energy Reviews, 75, 1339-1347.

3. Boyle, S. (1990). Transport and energy policies - only connect. Energy Policy, 18(1), 34-41.

4. Bruglieri, M., Bruschi, F., Colorni, A., Luè, A., Nocerino, R., \& Rana, V. (2015). A real-time information system for public transport in case of delays and service disruptions. Transportation Research Procedia, 10, 493-502.

5. Fedderke, J. W., Perkins, P., \& Luiz, J. M. (2006). Infrastructural investment in long-run economic growth: South Africa 1875-2001. World development, 34(6), 1037-1059.

6. Gao, Z., Wu, Y., \& Huang, J. (2009). Analysis of weld pool dynamic during stationary laser-MIG hybrid welding. The International Journal of Advanced Manufacturing Technology, 44(9-10), 870. 
7. Ghali, K. H., \& El-Sakka, M. I. (2004). Energy use and output growth in Canada: a multivariate cointegration analysis. Energy economics, 26(2), 225-238.

8. Johansen, S., \& Juselius, K. (1990). Maximum likelihood estimation and inference on cointegration - with applications to the demand for money. Oxford Bulletin of Economics and statistics, 52(2), 169-210.

9. Le Breton, É. (2001). Les compromis fragiles du traitement des conflits publics dans les transports urbains. Sociologie du travail, 43(4), 515-531.

10. Mbarek, M. B., Nasreen, S., \& Feki, R. (2017). The contribution of nuclear energy to economic growth in France: short and long run. Quality \& Quantity, 51(1), 219-238.

11. Pradhan, R. P., \& Bagchi, T. P. (2013). Effect of transportation infrastructure on economic growth in India: the VECM approach. Research in Transportation Economics, 38(1), 139-148.

12. Rojas-Rueda, D., De Nazelle, A., Teixidó, O., \& Nieuwenhuijsen, M. J. (2013). Health impact assessment of increasing public transport and cycling use in Barcelona: a morbidity and burden of disease approach. Preventive medicine, 57(5), 573-579.

13. Saidi, S., \& Hammami, S. (2017). Modeling the causal linkages between transport, economic growth and environmental degradation for 75 countries. Transportation Research Part D: Transport and Environment, 53, 415-427.

14. Sims, C. A. (1980). Macroeconomics and reality. Econometrica: Journal of the Econometric Society, 1-48.

15. Stelzer, A., Englert, F., Hörold, S., \& Mayas, C. (2016). Improving service quality in public transportation systems using automated customer feedback. Transportation Research Part E: Logistics and Transportation Review, 89, 259-271.

16. Wang, S., Fan, J., Zhao, D., Yang, S., \& Fu, Y. (2016). Predicting consumers' intention to adopt hybrid electric vehicles: using an extended version of the theory of planned behavior model. Transportation, 43(1), 123-143.

17. Xylia, M., \& Silveira, S. (2017). On the road to fossil-free public transport: The case of Swedish bus fleets. Energy Policy, 100, 397-412. 